\title{
Chapter 9 \\ eHealth Literacy and Capability \\ in the Context of the Pandemic Crisis
}

\author{
Dimitrios Kokkinakis
}

\subsection{Introduction}

This chapter presents an approach to eHealth literacy (eHL) inspired by research that uses the concept of capability as its point of departure. It highlights the importance of paying analytical attention to a wide range of variables related to older people's everyday lives in the face of the COVID-19 pandemic. The capability approach is a broad normative framework developed during the 1980s and onwards by the Indian philosopher, economist and Nobel laureate Amartya Sen (1999), and further developed by the philosopher Martha Nussbaum (2013). Capability or Capabilities are broadly understood as 'the individual's ability to perform actions in order to reach goals he or she has reason to value'. To achieve health equality and maintain good health under rapidly changing circumstances caused by, for example, a pandemic, and particularly in later life, there is a need to improve the potential for maximising individuals' capabilities, at both the societal and individual levels. The capability approach can be operationalised differently in different contexts, allowing individuals control over their own lives by taking into account the intersections of diversity, such as age and gender. The capability approach can offer a framework for the holistic conceptualisation of the importance of language and eHealth (literacy), stressing the importance of eHealth being inclusive and that eHL receives the necessary attention in order to minimise the risk of inducing or increasing health inequalities (Thulesius, 2020). It also offers an alternative paradigm which recognises that not all individuals will or can participate or benefit from the advice and recommendations given by public health agencies, expert committees, health

\footnotetext{
D. Kokkinakis $(\triangle)$

Department of Swedish, University of Gothenburg, Gothenburg, Sweden

Centre for Ageing and Health - AgeCap, University of Gothenburg,

Gothenburg, Sweden

e-mail: dimitrios.kokkinakis@svenska.gu.se
} 
managers and politicians in the same manner, nor can they generate the same or similar advantages in difficult circumstances, or life in general.

This chapter is divided into six main sections. The next section focuses on the notions of health literacy and eHL, highlighting the possible differences and commonalities and linking them to the capability framework, without going into a detailed discussion of the underlying theory. This section ends by discussing eHL in the pandemic scenario's paradoxical consequence of the infodemic, and how the scope of eHL can be enhanced in the light of experiences gained from COVID-19. Based on the three societal levels of AgeCap, i.e. micro, meso and macro, the third section explores eHealth within this research landscape, taking into consideration the application potential of eHL in this particular context. Methodological considerations and approaches that address eHL assessment and evaluation in general, and in the light of COVID-19 in particular, follow (Sect. 9.4). The chapter continues with a discussion and remarks on future perspectives on eHL within the COVID-19 pandemic scenario (Sect. 9.5), and Sect. 9.6 rounds off the chapter by presenting key take-home messages and conclusions.

\subsection{Health Literacy and eHealth Literacy}

\subsubsection{Definitions and the Operationalisation of eHL}

Although the definition of the broader term 'literacy' remains an open-ended question (Addey, 2017), health literacy has been defined in numerous overlapping and evolving ways. For instance, Mårtensson and Hensing (2012) identify two approaches to health literacy; one associated with the individual basic skills that are needed to understand health information and one that recognises a wide range of interactive skills within social and cultural contexts. In a series of papers, Sørensen (2019) and Sørensen et al. $(2012,2015)$ define health literacy as the knowledge, motivation and set of abilities required to access, understand, process, evaluate and use (basic) health information (and services) (from reliable sources) in order to make judgements and appropriate health decisions within the domains of healthcare, disease prevention and health promotion. All of this is in order to maintain or improve quality of life during the whole life course. Moreover, the rapid digitisation of healthcare and the wide availability of web-based and mobile health applications entail that in recent years health information has been increasingly sought through online and socially networked platforms (Dalmer, 2017). New competencies or 'literacies' are thus required in order to use such facilities properly and navigate effectively through the information space. These skills, required in additional to health literacy, are referred to as eHealth literacy (eHL) or electronic/digital health literacy. Thus, eHL is defined as 'the ability to seek, find, understand, and appraise health information from electronic sources and apply the knowledge gained to addressing or solving a health problem' (Norman \& Skinner, 2006:2). Since eHL comprises 
both general health literacy and digital skills, the correlation between eHL and health literacy is often moderate, exemplified by the fact that the various available instruments partly measure different skills (Neter et al., 2015). Norman and Skinner (2006) proposed a model that describes eHL as a combination of six different skills that are required to optimise patients' experiences with eHealth, namely:

analytical, i.e. skills required to participate in daily informational life:

'computer literacy' (to operate and use various digital devices),

'health literacy' (to perform tasks within the healthcare environment),

'scientific literacy' (the basic understanding of science-based information and concepts)

context-specific, i.e. skills centred on specific issues, problem types and contexts: 'information literacy' (knowledge about potential resources to consult), 'media literacy' (ability to critically assess media content and its sources), 'traditional literacy and numeracy' (the basic skills of reading and comprehension).

In recent years, health researchers have been expanding their scope to examine an even broader range of (literacy) skills, such as 'communication' (Norman, 2011; Rubin, 2017). Nevertheless, Norman (2011) proclaims that, although different contexts may introduce new challenges to building eHL, the core skills that form eHL are unlikely to change. Although general health literacy is an important aspect of public health, eHL has become a fast-emerging area of concern, especially in the era of the COVID-19 pandemic crisis. The pandemic puts more emphasis on some of these skills, particularly digital literacy, and the urge to make all of our social contacts digital. This has created a digital gap, whereby people who are not confident or competent in using digital technologies have been excluded from social connections, with negative consequences. The consequences of this social isolation have made it more difficult to access support with technology that would enable older people to connect digitally with family and friends (cf. Rosenberg et al., 2020).

Moreover, eHL is not like conventional literacy because we must invest fairly regularly in hardware and software, while at the same time continuously learning new things, because applications and interfaces are constantly changing. This can easily become a barrier for older people. Olsson et al. (2019) note that access to information and communication technology and literacy are strongly associated with resources, which decline with age, so that both access and literacy become a question of age and we cannot assume that contemporary 55-year-olds will remain equally included at the age of 85 or 95 . Such insights must be taken into account by policymakers because those who do not update their technology will be gradually excluded.

If one of the ideas about how to solve problems associated with an ageing population is to make more extensive use of digitalized public services and e-healthcare, then an awareness of the fact that such policies have significant limitations is essential. For a substantial proportion of older people, digitalization appears, in reality, to be a much less viable option. (Olsson et al., 2019: 68-69). 
A solution could be to pay additional attention to older people's everyday practices by specifically looking into the ways in which digital media are used and how. This could be achieved by conducting more in-depth surveys and interviews among older adult populations. This is likely to yield a better understanding of how current digital health information-seeking and sharing behaviours influence health-related decision-making.

\subsection{2 eHealth Literacy and Capability}

The capability approach describes the quality of life and well-being that individuals are able to achieve. In order to access such determinants, we should measure the abilities to achieve those 'beings and doings' that people have reason to value in life (Sen, 1993). Thus, the capability framework consists of all those internal (not readily observable, e.g. basic abilities and competences) and external (observable actions/skills, e.g. social norms, and the physical and social environment, such as work opportunities and a tolerant and secure political, economic and legal framework for action) factors that are necessary for a specific case of doing or being something.

Language barriers and low (eHealth) literacy at several levels (e.g. computer or scientific), as well as inadequate institutional and cultural competence, such as a lack of culturally competent healthcare providers, ${ }^{1}$ create obstacles to accessing and comprehending health information (Houwink et al., 2020). Therefore, an important internal factor affecting capability is the degree to which individuals have the capacity to obtain, process and understand basic health information and the services needed to make appropriate health-related decisions. Such information spans a broad range of important healthcare issues; for instance, by following instructions from a healthcare provider to manage the official recommendations of healthcare specialists before accepting them; or the ability to link knowledge about the potential health benefits and harms of particular behaviours and interventions for health outcomes.

More broadly, literacy has been given considerable attention in the work of Amartya Sen and Martha Nussbaum. According to Maddox (2008), Sen positions literacy within the hard core of 'basic capabilities', while Nussbaum includes literacy within her list of 'central human capabilities'; that is, internal factors that constitute a person's fundamental health (Tengland, 2020). Nowadays, a range of technology-based health tools and a range of devices for online connection and interaction permeate daily life, while the Internet has become an infrastructure for all kinds of services. With this in mind, we can stipulate that the more specific, subordinate aspects of literacy previously outlined, namely health literacy and eHealth

\footnotetext{
${ }^{1}$ For instance, one Swedish study showed that over $60 \%$ of newly arrived refugees had low health literacy (Wångdahl et al., 2014).
} 
literacy, are now also important and necessary core capabilities and functioning, necessary for human well-being and attaining a good life (cf. Sen, 2003). Various studies have highlighted the fact that limited health literacy and low-level eHL has consequences for the healthcare system at a macro level and is associated with poor health at the micro, a.k.a. personal, level (Abrams \& Farrell, 2011). Thus, healthcare providers and organisations need to be more active in developing and employing strategies to meet the language and literacy needs of diverse populations, including via online or other means of communication. For that matter, older adults' ability to perceive, comprehend and produce language has been an active area of interest to researchers in recent years. As such, eHL may be the means for achieving the goal of empowering people to make the right health-related decisions. According to various research studies (e.g. Jacobs et al., 2014; Geboers et al., 2016; Chesser et al., 2016), people with limited health literacy skills have less knowledge about their illness and its management. They tend to have higher rates of hospitalisation and readmission; are more likely to skip important preventive measures; enter the healthcare system when they are sicker; and make greater use of services designed to treat complications of disease and less use of services designed to prevent complications. Furthermore, the unforeseen consequences caused by the pandemic are accelerating research and development based on the importance of eHL and provoking a need to quickly and creatively re-think our modes of healthcare delivery. This includes embracing eHealth resources that connect care through the Internet and related technologies (Brørs et al., 2020). According to Fraser and Greenhalgh (2001) being capable can help an individual be adaptable, feel motivated and thus have resilience to stay through "tough times". Consequently, capability offers a "promise for striking the delicate balance between paternalism and autonomy' (Ruger, 2010:41). In this context, paternalism is the practice of the state interfering with the choices of an individual with the justification that the individual or population will be better off or protected from harm (e.g. lockdown-imposed isolation). Autonomy, based on Sen's view, is to live one's life according to one's own reasons and motivations and to have the ability to perform actions in order to reach goals that he or she has reason to value.

\subsubsection{Pandemic, Infodemic and eHealth Literacy}

Variations in eHL have been attributed to multiple determinants, ranging from education and older age to socioeconomic status (Garcia-Codina et al., 2019). Likewise, such variation is expected for pandemic-related eHL. ${ }^{2}$ The prevalence of covid-19 in socio-economically disadvantaged areas suggests that the consequences of the

\footnotetext{
${ }^{2}$ In Stockholm, for example, the lack of information about COVID-19 adapted for people with a foreign background has, among other things, been highlighted in the media as a contributing factor to the large number of infections in some social groups. According to the Stockholm Region, the incidence of COVID-19 cases was up to three times higher in the municipalities of Rinkeby-Kista
} 
disease (including mortality) follow a socio-economic gradient (USA Today, 2020; ITV news, 2020). An understanding of the levels and determinants of pandemicrelated eHL is essential to enable healthcare policymakers to formulate optimal strategies for the effective communication of critical medical information during the COVID-19 crisis and future pandemics. COVID-19 required targeted public information campaigns and the promotion of eHL at the population-based level for better navigation of the massively produced information space. This, in turn, created an infodemic (information epidemic), widespread false information, rumours and misleading health news on the Internet and social media platforms. According to Zarocostas (2020), the infodemic made it hard for everyone, and in particular the elderly population and suburban minority communities, to find trustworthy sources of information and reliable guidance when they needed it. The infodemic poses a significant threat to public health; for example, too much information can create confusion while at the same time vital behavioural changes need to be communicated in an understandable, transparent and consistent manner (Rubin \& Wessely, 2020). Thus, eHL can play a crucial role in enabling people to navigate the COVID-19 information environments and can aid informed decision-making about ways to address and prevent COVID-19.

Low eHL, particularly among older adults, is a critical determinant for reaching good and effective health outcomes. eHL focuses on individual capability and does imply that some skills are needed (Jacobs et al., 2014). In today's information and technology-rich healthcare environments, web-based and mobile applications are important for the dissemination of critical pandemic-related information. According to the United Nations (2020), the Internet and other digital technologies have become a window to the world during lockdown, enabling people to connect with family and friends. Moreover, in order for confidence in online health information and participation to increase (Ek et al., 2013), eHL needs to be constantly improved and thoughtfully considered. Inability to follow recommendations due to language and literacy barriers and a resultant lower use of preventative care measures may lead to increased costs and poorer outcomes.

Our eHL capabilities strengthen our capacity to be well informed about risks and recommendations and, ideally, to engage in solidarity-based behaviours in order to achieve improved public health (Paakkari \& Okan, 2020). Still, many older people have limited access to digital technologies and lack the necessary skills to fully exploit them. Even in developed countries, older adults living in institutions might also struggle to receive the necessary support to connect with their loved ones. Moreover, the older population is extremely diverse in many ways, from ability and age, to income and culture, and older people face numerous barriers, commonly related to language and eHL, which have been amplified during the pandemic. Therefore, using a variety of other communication formats, such as radio broadcasts and text messages, may ensure that critical information about measures to protect

and Tensta-Spånga (areas with a very high percentage of foreign-born population) than in the rest of Stockholm County (Tao, 2020). 
themselves from COVID-19 and how to access services reaches older people. Xie et al. (2020) point out that, to be effective, digital public health campaigns need to be linguistically and culturally attuned to such populations, and they recommend a number of actions. For instance: to develop digitally delivered training and interventions to improve older adults' eHL that are scalable and can be deployed rapidly; to develop informatics tools that are operational with basic technologies like telephones and work with low or intermittent Internet availability; and to train community health workers to be brokers of information, culture and technology for socially isolated (ethnic minority) older adults. According to Sentell et al. (2020:2), eHL is urgently needed by the public to be able to 'synthesize, analyze, and appraise the vast amount of urgent, complex, and even conflicting information from virologists, epidemiologists, data modelers, doctors, nurses, health departments, and the media' Although at the time of writing it is too early to have gold-standard instruments to evaluate pandemic-related eHL, some initiatives seem to be starting to take shape (cf. Sect. 9.4.3).

\subsubsection{The Scope of eHealth Literacy in the Pandemic Scenario}

The COVID-19 crisis has provided new opportunities to make eHealth sustainable and constitutes the best time to overcome cultural challenges, update regulations and improve interoperability between systems that has held back eHealth solutions and adoption for years (cf. Studzinski, 2020). COVID-19 has also created an urgent need to rapidly assess pandemic-related eHL by, for example, developing up-todate, validated and standardised questionnaires. eHL is vital to both slowing down the spread of this virus and mitigating its impact and effects, by making informed decisions about ways to address and prevent the disease. Little research is currently available regarding the effects of older adults' social isolation, their use of the Internet and social media to locate and evaluate health information, or the factors that influence their eHL and use of electronic information sources and other digital technologies for accessing and using health information. Further research is necessary to investigate the temporal relationship between COVID-19-related psychological well-being and the impact of the pandemic on mental health, such as anxiety, depression or suicidality, and whether psychological stressors during the pandemic persist well past the end of the outbreak (Chew et al., 2020; Kivi et al., 2020). Public leaders and policymakers need to be aware of these determinants and cautious about them when formulating and updating the dissemination strategies of critical pandemic-related information and interventions. More studies are required to evaluate the outcomes associated with pandemic-related eHL, taking account of the processes of seeking health information, and understanding, judging and applying such information. As previously outlined, this can be achieved by compensating for low eHL by adapting oral and written information into plain language and providing visual support and audio/video versions of the communication, thus balancing the depth of the information provided (see Sect. 9.4.1). 


\section{3 eHealth Literacy and the Three Societal Levels of AgeCap}

eHealth literacy is a research area relating to the three main societal levels that form the core of capability in ageing within the AgeCap framework, as indicated in accordingly in the introductory chapter of this book. To address (low) eHL, as previously discussed, we believe that there are three common-sense ways of considering the notion. Namely, (i) the macro level (with an emphasis on the organisational and policy components); (ii) the meso level (with an emphasis on technological resources) and (iii) the micro level (with an emphasis on socioeconomic factors and individual and interpersonal strengths and behaviours). These three levels overlap, and the model represents an oversimplification, but it provides a shared framework for understanding eHL.

The organisational and policy level, or the macro level. The digitisation of society at all levels affects what an individual can, should or prefers to do, and requires knowledge about how to handle, navigate and become a citizen of the digital world. For instance, how to access healthcare services and what literacy skills are required should be part of the laws and regulations to be enforced for all citizens of all ages (Zanobini et al., 2020). Political decisions, laws and regulations affect all the determinants of healthcare, including eHL. According to Brach (2017), for instance, a health-literate healthcare organisation is one that makes it easy for people to navigate, understand and use its information and services to take care of their own health. Brach also makes it clear that, even for pioneering organisations in health literacy, the opportunities for improvement are vast.

The technological resources and technological competence level, i.e. the meso level, is a necessity, acting as a 'glue' that develops, supports, enhances and promotes both (i) and (iii) (below). For instance, caring facilities and smart-home environments for older adults that support health, or the availability of suitable hardware and Internet access that can be both costly and even unavailable to older adults in many cases. In a survey of Swedish people aged 65-85, Olsson et al. (2019) showed that $80 \%$ of the respondents have some kind of device (mobile smartphone, laptop or tablet). Although the proportion of older people with access to such devices is higher in Sweden than in many other countries, Olsson et al. showed that the technological opportunities for this group are limited and dependent on various determinants, such as socioeconomic status, whereby increasing income increases the degree of access to information and communication. Their study also demonstrated that eHL is an important factor that explains sociodemographic effects such as age, education and household income on self-efficacy in utilising eHealth and frequency of eHealth information evaluation.

The individual and interpersonal level, i.e. the micro level. There is no health promotion and thus no health without eHL. Information transmission (digital or not) is not enough, other features such as cognitive functioning and the digital skills of information-seeking and decision-making need to be taught and practised. Furthermore, interventions aimed at promoting preventive health behaviours to 
avoid exposure to and transmission of COVID-19 must consider an individual's ability to receive, interpret and apply healthcare recommendations, according to their functional capacities, such as communication and social context. To ensure that older people understand what public health experts and politicians are saying or trying to convey poses significant challenges and the high degree of knowledge uncertainty at many levels makes COVID-19 news and official recommendations even more challenging. A major issue relates to concern about how the individual can integrate this sea of information into personal behavioural actions (Abel \& McQueen, 2020). In fact, some organisational stereotype-based decisions reinforce existing social inequalities related to factors such as ageism, which can lead to frustration, isolation and hopelessness. Older adults are a diverse and heterogeneous group. Fraser et al. (2020:2) note that the ageist attitudes circulating during COVID-19 make some people think that 'the pandemic is an older person's problem'. In addition, many countries, including Sweden, chose to impose stricter restrictions on older adults, ordering them to remain at home during the pandemic. ${ }^{3}$ These policies have often translated into patronising public communications depicting all older adults as 'vulnerable' members of society, while the fact may be that health professionals and policymakers lack eHL awareness and knowledge, since vulnerability could be just the result of limited financial resources, reduced mobility and/or social isolation.

Thus, a combination of all three levels outlined above is required in order to meet the unique needs and demands of eHL and facilitate an understanding of older people's perspectives and their capability to maintain good health, independence and well-being.

\subsection{Methodological Considerations}

\subsubsection{Tailoring Information and Plain Language}

In order to achieve better outcomes, the delivery of healthcare information needs to be tailored to meet older adults' health literacy needs and more must be invested in substantial technological and educational efforts. Also, developing or adapting computer-based instruments to screen older individuals accessing eHealth applications should be more highly prioritised. Computer-based algorithms that incorporate cultural and linguistic adaptations, for example (simplified) plain language (such as using familiar words and getting to the point quickly), and take a person's specific goals or needs into account, in addition to characteristics such as age, gender, ethnicity and reading ability, might prove efficacious. Therefore, plain language

\footnotetext{
${ }^{3}$ Nearly 10 months after the COVID-19 outbreak began (22 October 2020), the Swedish Public Health Agency's general advice for people aged 70 years or older was changed, and people aged 70 years or older are now covered by the general advice that applies to everyone.
} 
is a strategy for making written (and even oral) information easier to understand the first time it is read or heard (cf. health.gov 2015). Moreover, relevant technology has become available and boosted by several factors, such as the increasing interest in the accessibility and usability of digital health information, and the need to provide equal access and equal opportunity for people with diverse disabilities. In this respect, the roles of various available assistive technologies based on artificial intelligence and natural language processing have gained considerable importance, and there has been a growing number of scientific events targeting these questions. Examples include: the International Conference on Computers Helping People with Special Needs ${ }^{4}$ (ICCHP); Speech and Language Processing for Assistive Technologies ${ }^{5}$ (SLPAT); the International ACM Conference on Computers and Accessibility $^{6}$ (ASSETS); and the Workshop on Natural Language Processing for COVID-197 (NLP-COVID). However, available language resources and tools to develop such assistive technologies for older adults are scarce, and for frail older adults, i.e. persons who are experiencing a decline in human functioning (physical, psychological and social), even scarcer. ${ }^{8}$

In a more timely manner, the format and language of COVID-19 information also needs to evolve in order for it to be easy for older people to find, understand and use. Plain language principles offer a useful model for creating clear and concise written and verbal content. Natural language processing can play an important role in aspects such as readability assessments and improved textual accessibility through an understanding of a system's information flows and data practices, while tailoring to different audiences with concise, relevant, actionable and plain-text information is a practice that can be supported with existing technology (Kloehn et al., 2018). Thus, improving access to (digital or written) language is a central issue and the WHO (2020) has proposed several key principles for improving the understanding of health-related content. This is the case for health-related information that should be accessible to all members of society. Older adults, for instance, may have problems with technical jargon, scientific terms or search engines that do not return suitable results, or they may not be able to discern the quality of the information presented. Techniques for automatic text simplification and normalisation are available (Saggion, 2017) and can be targeted towards eHealth applications.

\footnotetext{
${ }^{4}$ https://www.icchp.org/

${ }^{5}$ http://www.slpat.org/

${ }^{6} \mathrm{https} / / / \mathrm{dl}$.acm.org/action/doSearch?AllField=International+ACM+Conference+on+Computers+ and+Accessibility

${ }^{7}$ https://openreview.net/group?id=aclweb.org/ACL/2020/Workshop/NLP-COVID

${ }^{8} \mathrm{~A}$ positive example moving in this direction was the Swedish government's decision in June 2020 to give extra funds to invest in digital solutions that can prevent the social exclusion of older people. According to Rosenberg et al. (2020), this resulted in some (Swedish) nursing homes revealing a tendency towards more 'spectacular' technological solutions, such as the use of a Yetitablet, a 65-inch Android tablet that is the equivalent of a large flat screen TV. This is a device that, according to Rosenberg et al., seems to be appreciated by care home residents, but a lack of competence among staff and some technical problems resulted in only a few being able to use this assistive technology.
} 
Thus, insufficient eHL can be reduced through increasing readability and comprehension by reducing the complexity of a text. Furthermore, developing more pictorial, audio and video content, instead of only presenting information in written format, became apparent as a complementary and efficient communication strategy to convey information about COVID-19.

\subsubsection{Training and Screening}

Screening instruments and evidence-based interventions can provide healthcare administrators and older adults with the necessary tools to reduce health disparities attributed to low eHL (Jacobs et al., 2014). Technological alternatives, such as audio-visual content (pictorial, diagrammatic, audio and video), in multilingual, interactive edutainment systems, available on a television screen or user-friendly web interfaces designed specifically for those with limited eHL, could allow older people to learn more about their conditions and how to take care of themselves.

Undoubtedly, eHL plays a crucial role in navigating the COVID-19 information environments. The importance of analytical strategies to measure the effectiveness of computer-based linguistic and culturally appropriate automated tailoring applications and eHL has already been stressed (Sentell et al., 2020). When time permits, society needs to invest more in technology education and provide continuous support, consultations and learning of best practices in the new technologies at libraries, education centres, seniors' union facilities and the like. Additional training is also required for specific older adult sub-groups to improve their digital literacy prior to eHealth interventions. Knowledge about technology can improve engagement and receptivity towards technological changes, which is crucial if digital interventions are to succeed (Mohammadyari \& Singh, 2015). Innovative technologies, such as touch screens (see footnote 8), sign-language interpreting services, and easy and clearly navigable websites, could help older adults to use the Internet to access health information. The NHS, for instance, recently launched its 'Digital Apps Library', a platform designed to bring together a number of digital tools that can be used for health and care, designed in a clear and easy to navigate way so that 'people of all ages and digital ability can move around it' (NHS, 2021). Also, the largest freely available collection of tools associated with the measurement or screening of (e)health literacy is the 'Health Literacy Tool Shed' database. ${ }^{9}$ As of this writing (mid-2020), the Tool Shed includes more than 200 tools.

Nevertheless, there will always be a segment of the population for whom information, however simplified, will still be difficult to fully comprehend and to whom tools and applications are inaccessible due to technological barriers. High-tech applications cannot completely replace face-to-face interaction for some older adults who need extra help (Bickmore et al., 2010), but technology is rapidly

\footnotetext{
${ }^{9}$ https://healthliteracy.bu.edu/
} 
maturing, and with appropriate coaching this can be feasible to a certain extent. Public authorities should offer their elderly residents opportunities to improve their digital skills and also involve older people in the design of technology. Some municipalities in Sweden ${ }^{10}$ have already taken the initiative to employ IT coaches who train and help the elderly with digital technology. These activities should be evaluated and disseminated on a much larger scale. Usability research conducted with older (frail) adults and their use of online health information resources and comprehensive and diagnostic measures of eHL are necessary. This can be accomplished by the validation of new (composite) scales and computer-based tools to assess eHL, which could evaluate older adults' familiarity with the Internet as reflected, in part, by the time spent online, and assess older adults' navigational knowledge and skills in using the Internet, specific to the use of eHealth applications (Watkins \& Xie, 2014). eHL screening in healthcare settings would be a beneficial tool in the care of older adults (Collins et al., 2012). For instance, eHL could be a way to measure older people's ability to understand basic hygiene practices to protect themselves, along with basic age-appropriate facts and information, including symptoms, complications, transmission and prevention. Paying attention to older people's eHL is key to improving health outcomes and lessening the impact of a pandemic at both the individual and societal levels (Brørs et al., 2020), enabling stakeholders to tailor eHealth applications to user needs.

\subsubsection{Instruments and Measures}

Health literacy is measured through both performance and self-report (Collins et al., 2012), but there is a much smaller range of tools available for assessing consumers' levels of eHL and no consensus on the most appropriate eHL measure. Existing scales vary in terms of evaluation approach and administration time, while some require considerable amounts of technical equipment; therefore, their main use has been in exploratory research or for the validation of self-rating instruments (Quinn et al., 2017).

The eHealth Literacy Scale (eHEALS), developed by Norman and Skinner (2006), is designed to capture the six different aspects of eHL already discussed (Sect. 9.2.1). eHEALS measures perceived knowledge, skills and confidence in locating, evaluating and using electronic health information in order to make health-related decisions. However, factors such as information or operational and strategic Internet competencies are not included in this instrument (van der Vaart et al., 2011). Identified gaps are addressed by the eHealth Literacy Framework (eHLF), developed by Norgaard et al. (2015). eHLF, for instance, measures the ability to engage with digital services (e.g. navigation skills); the ability to 'feel safe and in control' (e.g. trust in the information available on the Internet); and the domain

\footnotetext{
${ }^{10}$ https://seniornet.se/
} 
of digital services that suits individual needs (e.g. the language, interface, relevance of information, its quality and simplicity of language). Variations of eHEALS also include the eHealth Literacy Assessment Toolkit (eHLA) developed by Furstrand and Kayser (2015), which measures 'functional health literacy' (i.e. reading comprehension and numeracy skills in a health context); 'familiarity with technology' and 'technology confidence'. The Digital Health Literacy Instrument (DHLI) developed by van der Vaart and Drossaert (2017) uses a set of items in response to the need for more objective measures of eHL, such as 'operational skills', 'navigation skills', 'information searching skills' and 'adding self-generated content'. According to van der Vaart and Drossaert, previous eHL measurement instruments have measured only competencies related to searching for and using online health information, while DHLI was designed to pay more attention to interactivity on the Internet. The eHealth Literacy Questionnaire (eHLQ), a multidimensional tool based on the eHLF, has been used to understand and evaluate people's interactions with digital health services (Kayser et al., 2018). The eHLQ captures dimensions that describe the attributes of the users, the intersection between users and the technologies and users' experience of systems. Finally, the Transactional eHealth Literacy Instrument (TeHLI) is one of the most recent measures of eHL (Paige et al., 2019). eHL is operationalised through four literacies; namely: (1) 'functional eHL' (basic skills in reading and writing/typing about health); (2) 'communicative eHL' (the ability to collaborate, adapt and control communication about health with users in social online environments); (3) 'critical eHL' (the ability to evaluate the credibility, relevance and risks of sharing and receiving health information on the Internet); and (4) 'translational eHL' (the highest cognitive level of eHL, informed and built upon the three previous dimensions). For a review of other related tools, such as the Health Literacy Screening Question Methodologies (HLSQM) and the Brief Health Literacy Screeners (BHLS), see Pleasant et al. (2019).

Tests are not always transferable to other languages, cultures or linguistic contexts. The best thinkable scenario is the one that can facilitate comparisons and generalisations and thus use internationally developed tools that can be applied to several languages (Mantwill et al., 2018). A good example is the European Health Literacy Survey Questionnaire (HLS-EU-Q). This is an efficient instrument for measuring comprehensive health literacy. Since its original version, which contained 86 variables, shorter forms have been developed, with 47 or 16 measurable indicators; the latter being the HLS-EU-Q16, which has been adapted for use in the Swedish language.

Currently, there are no gold-standard instruments to evaluate pandemic-related eHL, only health literacy. Okan et al. (2020) proposed COVID-19-related health literacy measures and developed a tool for assessing coronavirus-related health literacy in population surveys (HLS-COVID-Q22). In a cross-sectional online survey, Okan et al. (2020) found that confusion about COVID-19 information was significantly higher among those who had lower eHL. Wolf et al. (2020) evaluated the health literacy related to COVID-19 among high-risk populations, such as the elderly, and found varying levels of pandemic-related health literacy. In their study of COVID-19 awareness and attitudes among chronic disease patients in the USA, 
it was particularly alarming to note that one-third of participants were unable to identify symptoms associated with COVID-19, and roughly one-quarter of participants felt that they were unlikely to be infected by the virus.

\subsection{Discussion}

In this brief scoping review (Munn et al., 2018), we have provided an overview of eHL and its relation to the extraordinary circumstances arising from the COVID-19 pandemic, positioning older people's empowerment and well-being at the forefront. The theoretical framework that the study has tried to assess is the capability approach to eHL, a theory that can be operationalised differently in different contexts. The study has touched upon some of the mechanisms that can be applied in this area, pinpointing the fact that the eHL challenge is a shared responsibility between the health sector, civil society and policymakers. In this respect, eHL should be at the top of the agenda in discussions about healthcare (Brørs et al., 2020) and successful implementation of e-health interventions (e.g. devices and their implementation) should be tailored to target different attitudes, needs and preferences, with a strong focus on information and support for older adults. Reiners et al. (2019) summarise these needs as follows: the eHealth devices should be personalised and tailored to the target user group; easy access to the Internet should be provided and family members should be involved in the use of the eHealth devices. Although there is a rising trend of supporting eHealth, older people, including in Sweden, describe feelings of ambivalence, raising 'concerns [about] accessibility to health care, mistrust in poor IT systems or impaired abilities to cope with technology' (Milos Nymberg et al., 2019: 50). Improving eHL at an individual and population level is therefore a priority area for research (Car et al., 2017). This is indirectly mirrored in the Swedish government's vision ('Vision e-health 2025', 2016), which states that by 2025 Sweden will be the best in the world at using the possibilities of digitalisation in order to (a) facilitate people to achieve good and equal health and welfare and (b) develop and strengthen their own resources for increased independence and participation in community life.

The older population is an incredibly diverse group, with chronological age being only loosely correlated to biological age. Healthcare providers must recognise the individual eHL capabilities of older adults and tailor their approach to meet their specific needs. COVID-19 has forced a major step-change in utilising eHealth and revealed the necessity for better navigation of information environments during the infodemic (Okan et al., 2020). However, seeking information on the Internet can be especially complex because it requires general knowledge about the topic of interest, basic knowledge of hardware and software operations, information-seeking skills (e.g., knowledge of how a web page's content is organised) and the ability to judge whether information sources are credible. It is thus of critical importance that healthcare providers take into consideration the older population's eHL skills in order to promote a higher degree of activation and support for the elderly to 
self-manage their own mental and physical health during a pandemic. It is also essential that policies, programmes and communications provide a differentiated, undistorted picture of the impact of the pandemic on older people and their contribution to the response to ensure they are not being stigmatised. As this chapter has highlighted, greater access to reliable health information is not necessarily achieved if it is in written form or plain language alone. Organisations should develop content in various formats, recognising that pictorial, audio and video content is easier for many people to access and absorb (United Nations, 2020). The literature points out that there is a need for more research into the intersection of the social determinants of health in the preparation for, response during and recovery from a pandemic. It is also imperative that future research is undertaken to evaluate levels of eHL among various groups of older people and to extend our knowledge about each of the relevant determinants in order to devise solutions to address the risk factors and assist decision-makers in their attempts to meet the identified needs of populations who are negatively affected by a pandemic. For instance, health authorities and policymakers should routinely conduct eHL reports to assess the preparedness of individuals and societies for any disease outbreak and to strengthen the public health environment and policies (Abdel-Latif, 2020).

Sen's theory aims to expand individual capability (Sen, 1999). It is recommended to examine how eHL is performed in large longitudinal studies after the first wave of the pandemic is over. Moreover, the terms used to describe high-risk groups are important, particularly in terms of framing vulnerability. As in the case of previous pandemics, most people prefer not to be labelled 'vulnerable' and, as O'Sullivan and Bourgoin (2010:22) emphasise, 'part of promoting resiliency is providing empowerment. Being at risk does not necessarily imply vulnerability, if appropriate supports are available.' Therefore, it is important to pay additional attention to older people's everyday practices. In-depth surveys and interviews among older adult populations are likely to yield a better understanding of how current digital health information-seeking and sharing behaviours influence health-related decisionmaking. Specifically, we need to look into the ways in which digital media are used (Olsson et al., 2019), using both statistical measurements and data derived from interviews and observations of the everyday lives of older people. In addition, older people should be involved early in the design of technology. Among other things, this would offer researchers the opportunity to also listen to and analyse their own reflections on what it means to grow older in a digitalising society and, particularly, in the context of a pandemic.

\subsection{Conclusions}

In this chapter, we have identified and described an important factor in the context of the incorporation of eHealth into social and healthcare services for older people; namely, of eHL and its relation to health-promoting behaviours among older adults within the capability approach. We have further examined some aspects and research 
highlighting the importance and direct correlation between eHL and quality of life for older adults in the capability context. Finally, we used the COVID-19 pandemic as a context within which to specifically and explicitly discuss the opportunities, challenges and future directions for rapidly developing, scaling up and enhancing eHealth for the benefit of older people. Previous research has identified the lack of eHL among older people as a significant barrier to the integration of informatics content into the healthcare context. The capability approach may offer a framework for the holistic conceptualisation of barriers and solutions to problems faced, regardless of whether these are language or technology dependent, and also provide mechanisms and tools for increasing the capacity of each individual in order to reach goals that he or she has reason to value. Further research on eHL is required in order to facilitate a better understanding of the information needs of older people; for instance, how they seek and use information about COVID-19. Of equal importance is the political attention that must be given to policies supporting the enhancement of eHL in order to avoid future risks and problems due to the impact of rumours and misinformation by providing easy-to-access and easy-to-use information. We also need to explore possible alternative ways to support older people in their use of the technologies they want and need to use in their everyday lives.

The limitations of this scoping review are derived from the low availability of rigorous scientific evidence on the topic of eHL within the pandemic framework, although for the time being there is an intense flow of COVID-19-related information and research in this direction. Therefore, the choice of methodology can be justified because it attempts to clarify some concepts and broaden the scope of eHL. Moreover, justification can also be established based on the growing body of various kinds of scientific literature about the lack of stable recommendations with a risk of biased information.

\section{References}

Abdel-Latif, M. (2020). The enigma of health literacy and COVID-19 pandemic. Public Health, 185, 95-96. https://doi.org/10.1016/j.puhe.2020.06.030

Abel, T., \& McQueen, D. (2020). Critical health literacy and the COVID-19 crisis. Health Promotion International, 1-2. https://doi.org/10.1093/heapro/daaa040

Abrams, L., \& Farrell, M. T. (2011). Language processing in normal aging. In J. Guendouzi et al. (Eds.), The handbook of psycholinguistic and cognitive processes: Perspectives in communication disorders (pp. 49-73). Psychology Press: Taylor and Francis.

Addey, C. (2017). Assembling literacy as global: The danger of a single story. In M. Milana et al. (Eds.), The Palgrave international handbook on adult and lifelong education and learning (pp. 315-335). Palgrave Macmillan.

Bickmore, T. W., Pfeifer, L. M., Byron, D., Forsythe, S., Henault, L. E., Jack, B. W., Silliman, R., \& Paasche-Orlow, M. K. (2010). Usability of conversational agents by patients with inadequate health literacy: Evidence from two clinical trials. Journal of Health Communication, 15(2), 197-210. https://doi.org/10.1080/10810730.2010.499991

Brach, C. (2017). The journey to become a health literate organization: A snapshot of health system improvement. Studies in Health Technology and Informatics, 240, 203-237. https://doi.org/10.3233/978-1-61499-790-0-203 
Brørs, G., Norman, C. D., \& Norekvål, T. M. (2020). Accelerated importance of eHealth literacy in the COVID-19 outbreak and beyond. European Journal of Cardiovascular Nursing, 19, 458. https://doi.org/10.1177/1474515120941307

Car, J., Shin Tan, W., Huang, Z., Sloot, P., \& Dean Franklin, B. (2017). eHealth in the future of medications management: Personalisation, monitoring and adherence. BMC Medicine, 15, 73. https://doi.org/10.1186/s12916-017-0838-0

Chesser, A. K., Keene Woods, N., Smothers, K., \& Rogers, N. (2016). Health literacy and older adults: A systematic review. Gerontology and Geriatric Medicine, 15, 2. https://doi. org/10.1177/2333721416630492

Chew, Q. H., Wei, K. C., Vasoo, S., \& Chua, H. C. (2020). Narrative synthesis of psychological and coping responses towards emerging infectious disease outbreaks in the general population: Practical considerations for the Covid-19 pandemic. Singapore Medical Journal, 61(7), 350-356. https://doi.org/10.11622/smedj.2020046

Collins, S. A., Currie, L. M., Bakken, S., Vawdrey, D. K., \& Stone, P. W. (2012). Health literacy screening instruments for eHealth applications: A systematic review. Journal of Biomedical Informatics, 45(3), 598-607. https://doi.org/10.1016/j.jbi.2012.04.001

Dalmer, N. K. (2017). Questioning reliability assessments of health information on social media. Journal of the Medical Library Association, 105(1), 61-68. https://doi.org/10.5195/ jmla.2017.108

Ek, S., Eriksson-Backa, K., \& Niemelä, R. (2013). Use of and trust in health information on the internet: A nationwide eight-year follow-up survey. Informatics for Health \& Social Care, 38(3), 236-245. https://doi.org/10.3109/17538157.2013.764305

Fraser, S. W., \& Greenhalgh, T. (2001). Coping with complexity: Educating for capability. BMJ, 323(7316), 799-803. https://doi.org/10.1136/bmj.323.7316.799

Fraser, S., Lagacé, M., Bongué, B., Ndeye, N., Guyot, J., Bechard, L., Garcia, L., Taler, V., CCNA Social Inclusion and Stigma Working Group, Adam, S., Beaulieu, M., Bergeron, C. D., Boudjemadi, V., Desmette, D., Donizzetti, A. R., Éthier, S., Garon, S., Gillis, M., Levasseur, M., Lortie-Lussier, M., Marier, P., Robitaille, A., Sawchuk, K., Lafontaine, C., \& Tougas, F. (2020). Ageism and COVID-19: What does our society's response say about us? Age and Ageing, 49, 692. afaa097. https://doi.org/10.1093/ageing/afaa097

Furstrand, D., \& Kayser, L. (2015). Development of the eHealth literacy assessment toolkit, eHLA. Studies in Health Technology and Informatics, 216, 971.

Garcia-Codina, O., Juvinyà-Canal, D., Amil-Bujan, P., Bertran-Noguer, C., González-Mestre, M. A., Masachs-Fatjo, E., Santaeugènia, S. J., Magrinyà-Rull, P., \& Saltó-Cerezuela, E. (2019). Determinants of health literacy in the general population: Results of the Catalan health survey. BMC Public Health, 19(1), 1122. https://doi.org/10.1186/s12889-019-7381-1

Geboers, B., Reijneveld, S. A., Jansen, C., \& de Winter, A. F. (2016). Health literacy is associated with health behaviours and social factors among older adults: Results from the LifeLines cohort study. Journal of Health Communication, 21(2), 45-53.

health.gov - US Department of Health and Human Services, Office of Disease Prevention and Health Promotion. (2015). Health literacy online: A guide to simplifying the user experience. https://health.gov/our-work/health-literacy. Accessed 08 Aug 2020.

Houwink, E. J. F., Kasteleyn, M. J., Alpay, L., Pearce, C., Butler-Henderson, K., Meijer, E., van Kampen, S., Versluis, A., Bonten, T. N., van Dalfsen, J. H., van Peet, P. G., Koster, Y., Hierck, B. P., Jeeninga, I., van Luenen, S., van der Kleij, R. M. J. J., Chavannes, N. H., \& Kramer, A. W. M. (2020). SERIES: eHealth in primary care. Part 3: eHealth education in primary care. The European Journal of General Practice, 26, 1. https://doi.org/10.1080/13814788. 2020.1797675

ITV news. (2020). Covid: Why ethnic minority groups have been hit hardest by coronavirus. 14 Dec. Available at: https://www.itv.com/news/2020-12-14/covid-why-ethnic-minority-groupshave-been-hit-hardest-by-coronavirus. Accessed 21 Dec 2020.

Jacobs, R. J., Lou, J. Q., Ownby, R. L., \& Caballero, J. (2014). A systematic review of eHealth interventions to improve health literacy. Health Informatics Journal, 22(2), 81-98. https://doi.org/10.1177/1460458214534092 
Kayser, L., Karnoe, A., Furstrand, D., Batterham, R., Christensen, K. B., Elsworth, G., \& Osborne, R. H. (2018). A multidimensional tool based on the eHealth literacy framework: Development and initial validity testing of the eHealth literacy questionnaire (eHLQ). Journal of Medical Internet Research, 20(2), e36. https://doi.org/10.2196/jmir.8371

Kivi, M., Hansson, I., \& Bjälkebring, P. (2020). Up and about: Older adults' Well-being during the COVID-19 pandemic in a Swedish longitudinal study. The Journals of Gerontology: Series B, 76, e4. gbaa084. https://doi.org/10.1093/geronb/gbaa084

Kloehn, N., Leroy, G., Kauchak, D., Gu, Y., Colina, S., Yuan, N. P., \& Revere, D. (2018). Improving consumer understanding of medical text: Development and validation of a new subsimplify algorithm to automatically generate term explanations in English and Spanish. Journal of Medical Internet Research, 20(8), e10779.

Maddox, B. (2008). What good is literacy? Insights and implications of the capabilities approach. Journal of Human Development and Capabilities, 9(2), 185-206. https://doi. org/10.1080/14649880802078736

Mantwill, S., Allam, A., Camerini, A.-L., \& Schulz, P. J. (2018). Validity of three brief health literacy screeners to measure functional health literacy: Evidence from five different countries. Journal of Health Communication, 23(2), 153-161. https://doi.org/10.1080/1081073 0.2017 .1417515

Mårtensson, L., \& Hensing, G. (2012). Health literacy: A heterogeneous phenomenon: A literature review. Scandinavian Journal of Caring Sciences, 26(1), 151-160. https://doi.org/10.1111/j.1471-6712.2011.00900.x

Milos Nymberg, V., Borgström Bolmsjö, B., Wolff, M., Calling, S., Gerward, S., \& Sandberg, M. (2019). 'Having to learn this so late in our lives...' Swedish elderly patients' beliefs, experiences, attitudes and expectations of e-health in primary health care. Scandinavian Journal of Primary Health Care, 37(1), 41-52. https://doi.org/10.1080/02813432.2019.1570612

Mohammadyari, S., \& Singh, H. (2015). Understanding the effect of e-learning on individual performance: The role of digital literacy. Computers in Education, 82, 11-25. https://doi.org/10.1016/j.compedu.2014.10.025

Munn, Z., Peters, M. D. J., Stern, C., Tufanaru, C., McArthur, A., \& Aromatari, E. (2018). Systematic review or scoping review? Guidance for authors when choosing between a systematic or scoping review approach. BMC Medical Research Methodology, 18, 143. https://doi.org/10.1186/s12874-018-0611-x

Neter, E., Brainin, E., \& Baron-Epel, O. (2015). The dimensionality of health literacy and eHealth literacy. European Journal of Health Psychology, 17(6), 275-280.

NHS Digital Apps Library. (2021). https://www.nhs.uk/apps-library/. Accessed 18 Jan 2021.

Norgaard, O., Furstrand, D., Klokker, L., Karnoe, A., Batterham, R., Kayser, L., \& Osborne, R. H. (2015). The e-health literacy framework: A conceptual framework for characterizing e-health users and their interaction with e-health systems. Knowledge Management \& E-Learning, 7(4), 522-540. https://doi.org/10.34105/j.kmel.2015.07.035

Norman, C. D. (2011). eHealth literacy 2.0: Problems and opportunities with an evolving concept. Journal of Medical Internet Research, 13(4), e125. https://doi.org/10.2196/jmir.2035

Norman, C. D., \& Skinner, H. A. (2006). eHealth literacy: Essential skills for consumer health in a networked world. Journal of Medical Internet Research, 8(2), e9. https://doi.org/10.2196/ jmir.8.2.e9

Nussbaum, M. C. (2013). Creating capabilities: The human development approach. Belknap Press: An Imprint of Harvard University Press.

O'Sullivan, T., \& Bourgoin, M. (2010). Vulnerability in an influenza pandemic: Looking beyond medical risk. Behaviour. 11:16. Available online at: https://homelesshub.ca/resource/ vulnerability-influenza-pandemic-looking-beyond-medical-risk [Google Scholar]

Okan, O., Bollweg, T. M., Berens, E.-M., Hurrelmann, K., Bauer, U., \& Schaeffer, D. (2020). Coronavirus-related health literacy: A cross-sectional study in adults during the COVID-19 infodemic in Germany. International Journal of Environmental Research and Public Health, 17, 5503. https://doi.org/10.3390/ijerph17155503 
Olsson, T., Samuelsson, U., \& Viscovi, D. (2019). At risk of exclusion? Degrees of ICT access and literacy among senior citizens. Information, Communication \& Society, 22(1), 55-72. https://doi.org/10.1080/1369118X.2017.1355007

Paakkari, L., \& Okan, O. (2020). COVID-19: Health literacy is an underestimated problem. Lancet, 5(5), e249-e250. https://doi.org/10.1016/S2468-2667(20)30086-4

Paige, S. R., Stellefson, M., Krieger, J. L., Miller, M. D., Cheong, J., \& Anderson-Lewis, C. (2019). Transactional eHealth literacy: Developing and testing a multi-dimensional instrument. Journal of Health Communication, 24(10), 737-748. https://doi.org/10.1080/10810730.2019.1666940

Pleasant, A., Maish, C., O'Leary, C., \& Carmona, R. (2019). Measuring health literacy in adults: An overview and discussion of current tools. In O. Okan, U. Bauer, D. Levin-Zamir, P. Pinheiro, \& K. Sørensen (Eds.), International handbook of health literacy (pp. 67-81). Policy Press Imprint of Bristol University Press.

Quinn, S., Bond, R., \& Nugent, C. (2017). Quantifying health literacy and eHealth literacy using existing instruments and browser-based software for tracking online health information seeking behavior. Computers in Human Behavior, 69, 256-267. https://doi.org/10.1016/j. chb.2016.12.032

Reiners, F., Sturm, J., Bouw, L. J. W., \& Wouters, E. J. M. (2019). Sociodemographic factors influencing the use of eHealth in people with chronic diseases. International Journal of Environmental Research and Public Health, 16(4), 645. https://doi.org/10.3390/ijerph16040645

Rosenberg, L., Nygård, L., Josephsson, S., Walles Malinowsky, C. (2020). Consequences of digital exclusion: Reflections from Sweden. The 30th Alzheimer Europe Conference. P16.04.

Rubin, D. L. (2017). Listenability as a tool for advancing health literacy. Journal of Health Communication, 17(Suppl 3), 176-190. https://doi.org/10.1080/10810730.2012.71262

Rubin, G. J., \& Wessely, S. (2020). The psychological effects of quarantining a city. BMJ, 368, m313. https://doi.org/10.1136/bmj.m313

Ruger, J. P. (2010). Health capability: Conceptualization and operationalization. American Journal of Public Health, 100(1), 41-49. https://doi.org/10.2105/AJPH.2008.143651

Saggion, H. (2017). Automatic text simplification. Synthesis Lectures on Human Language Technologies. Hirst G (series ed) Morgan \& Claypool Publishers San Rafael.

Sen, A. K. (1993). Capability and Well-being. In M. Nussbaum \& A. Sen (Eds.), The quality of life. Clarendon Press. https://doi.org/10.1093/0198287976.001.0001

Sen, A. K. (1999). Development as freedom. Oxford University Press.

Sen, A. K. (2003). Reflections on literacy. In C. Robinson (Ed.), Literacy as freedom (pp. 21-30). UNESCO.

Sentell, T., Vamos, S., \& Okan, O. (2020). Interdisciplinary perspectives on health literacy research around the world: More important than ever in a time of COVID-19. Journal of Environmental Research and Public Health, 17, 3010. https://doi.org/10.3390/ijerph17093010

Sørensen, K. (2019). Defining health literacy: Exploring differences and commonalities. In O. Okan, U. Bauer, D. Levin-Zamir, P. Pinheiro, \& K. Sørensen (Eds.), International handbook of health literacy (pp. 5-20). Policy Press Imprint of Bristol University Press.

Sørensen, K., van den Broucke, S., Fullam, J., Doyle, G., Pelikan, J., Slonska, Z., Brand, H., \& (HLS-EU) Consortium Health Literacy Project European. (2012). Health literacy and public health: A systematic review and integration of definitions and models. BMC Public Health, 12, 80. https://doi.org/10.1186/1471-2458-12-80

Sørensen, K., Pelikan, J. M., Röthlin, F., Ganahl, K., Slonska, Z., Doyle, G., Fullam, J., Kondilis, B., Agrafiotis, D., Uiters, E., Falcon, M., Mensing, M., Tchamov, K., van den Broucke, S., Brand, H., \& HLS-EU Consortium. (2015). Health literacy in Europe: Comparative results of the European health literacy survey (HLS-EU). European Journal of Public Health, 25(6), 1053-1058. https://doi.org/10.1093/eurpub/ckv043

Studzinski, J. (2020). eHealth study: Non-clinical telehealth services are most prevalent, but COVID-19 accelerates new trends. Healthcare Information and Management Systems Society, Inc (HIMSS) Available via: www.himss.org/news/ehealth-study-non-clinical-telehealthservices-are-most-prevalent-covid-19-a-new. Accessed 02 Aug 2020. 
Tao, W. (2020). Coronapandemin och socioekonomiska skillnader - En prognos om kortoch långsiktiga effecter (Corona pandemic and socio-economic disparities: A forecast of short- and long-term effects). Center for Epidemiology and Community Medicine (In Swedish). Available at: https://www.folkhalsoguiden.se/globalassets/verksamheter/ forskning-och-utveckling/centrum-for-epidemiologi-och-samhallsmedicin/folkhalsoguiden/ rapporter-och-faktablad/coronapandemin-och-socioekonomiska-skillnader\%2D\%2D-enprognos-om-kort\%2D\%2Doch-langsiktiga-effekter_.pdf. Accessed 25 Aug 2020.

Tengland, P. (2020). Health and capabilities: A conceptual clarification. Medicine Health Care and Philosophy, 23, 25-33. https://doi.org/10.1007/s11019-019-09902-w

Thulesius, H. (2020). Increased importance of digital medicine and eHealth during the Covid-19. Scandinavian Journal of Primary Health Care, 38(2), 105. https://doi.org/ $10.1080 / 02813432.2020 .1770466$

United Nations. (2020). Policy brief: The impact of COVID-19 on older persons. https://unsdg.un.org/sites/default/files/2020-05/Policy-Brief-The-Impact-of-COVID-19-onOlder-Persons.pdf. Accessed 01 Aug 2020.

USA Today. (2020). An unbelievable chain of oppression: America's history of racism was a preexisting condition for COVID-19. 22 Oct. Available at: https://eu.usatoday.com/in-depth/news/ nation/2020/10/12/coronavirus-deaths-reveal-systemic-racism-united-states/5770952002/. Accessed 21 Dec 2020.

van der Vaart, R., \& Drossaert, C. (2017). Development of the digital health literacy instrument: Measuring a broad spectrum of health 1.0 and health 2.0 skills. Journal of Medical Internet Research, 19(1), e27. https://doi.org/10.2196/jmir.6709

van der Vaart, R., van Deursen, A. J., Drossaert, C. H., Taal, E., van Dijk, J. A., \& van de Laar, M. A. (2011). Does the eHealth literacy scale (eHEALS) measure what it intends to measure? Validation of a Dutch version of the eHEALS in two adult populations. Journal of Medical Internet Research, 13(4), e86. https://doi.org/10.2196/jmir.1840

Vision e-health 2025. (2016). Regeringskansliet. Stockholm. Socialdepartementet (In Swedish) https://www.regeringen.se/informationsmaterial/2016/04/vision-e-halsa-2025/. Accessed 21 Aug 2020.

Wångdahl, J., Lytsy, P., Mårtensson, L., \& Westerling, R. (2014). Health literacy among refugees in Sweden: A cross-sectional study. BMC Public Health, 14, 1030. https://doi.org/10.1186/ 1471-2458-14-1030

Watkins, I., \& Xie, B. (2014). eHealth literacy interventions for older adults: A systematic review of the literature. Journal of Medical Internet Research, 16(11), e225. https://doi.org/10.2196/ jmir.3318

WHO. (2020). Tactics to apply to make your communications understandable. https://www.who. int/about/communications/understandable. Accessed 13 Aug 2020.

Wolf, M. S., Serper, M., Opsasnick, L., O'Conor, R. M., Curtis, L. M., Benavente, J. Y., Wismer, G., Batio, S., Eifler, M., Zheng, P., Russell, A., Arvanitis, M., Ladner, D., Kwasny, M., Persell, S. D., Rowe, T., Linder, J. A., \& Bailey, S. C. (2020). Awareness, attitudes, and actions related to COVID-19 among adults with chronic conditions at the onset of the US outbreak: A crosssectional survey. Annals of Internal Medicine, 173, 100. https://doi.org/10.7326/m20-1239

Xie, B., Charness, N., Fingerman, K., Kaye, J., Kim, M. T., \& Khurshid, A. (2020). When going digital becomes a necessity: Ensuring older adults' needs for information, services, and social inclusion during COVID-19. Journal of Aging \& Social Policy, 32, 4-5. https://doi.org/ $10.1080 / 08959420.2020 .1771237$

Zanobini, P., Lorini, C., Baldasseroni, A., Dellisanti, C., \& Bonaccorsi, G. (2020). A scoping review on how to make hospitals health literate healthcare organizations. International Journal of Environmental Research and Public Health, 17(3), 1036. https://doi.org/10.3390/ ijerph17031036

Zarocostas, J. (2020). How to fight an infodemic. Lancet, 395, 10225. https://doi.org/10.1016/ S0140-6736(20)30461-X 
Open Access This chapter is licensed under the terms of the Creative Commons Attribution 4.0 International License (http://creativecommons.org/licenses/by/4.0/), which permits use, sharing, adaptation, distribution and reproduction in any medium or format, as long as you give appropriate credit to the original author(s) and the source, provide a link to the Creative Commons license and indicate if changes were made.

The images or other third party material in this chapter are included in the chapter's Creative Commons license, unless indicated otherwise in a credit line to the material. If material is not included in the chapter's Creative Commons license and your intended use is not permitted by statutory regulation or exceeds the permitted use, you will need to obtain permission directly from the copyright holder.

(c) () 